\title{
Effect on VA Patient Satisfaction of Provider's Use of an Integrated Viewer of Multiple Electronic Health Records
}

\author{
Aaron Legler, MS ${ }^{7}$, Megan Price, $M S^{7}$, Megha Parikh, $M P H^{7}$, Jonathan R. Nebeker, MS MD2,3,4, \\ Merry C. Ward, $P h D^{4}$, Linda Wedemeyer, $M D^{4}$, and Steven D. Pizer, $P h D^{1,5}$
}

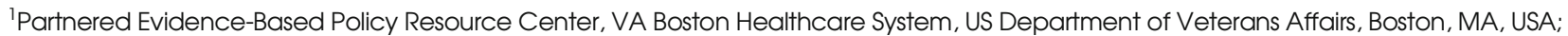
${ }^{2}$ Department of Medicine, University of Utah School of Medicine, Salt Lake City, UT, USA; ${ }^{3}$ Geriatric Research and Education Clinical Center, VA Salt Lake City Health Care System, US Department of Veterans Affairs, Salt Lake City, UT, USA; ${ }^{4}$ Office of Health Informatics, US Department of Veterans Affairs, Los Angeles, CA, USA; ${ }^{5}$ Department of Health Law, Policy, and Management, Boston University School of Public Health, Boston, MA, USA.

PURPOSE: To examine associations between patient perceptions that their provider was knowledgeable of their medical history and clinicians' early adoption of an application that presents providers with an integrated longitudinal view of a patient's electronic health records (EHR) from multiple healthcare systems.

METHOD: This retrospective analysis utilizes provider audit logs from the Veterans Health Administration Joint Legacy Viewer (JLV) and patient responses to the Survey of Patient Healthcare Experiences Patient-Centered Medical Home (SHEP/PCMH) patient satisfaction survey (FY2016) to assess the relationship between the primary care provider being an early adopter of JLV and patient perception of the provider's knowledge of their medical history. Multivariate logistic regression models were used to control for patient age, race, sex education, health status, duration of patient-provider relationship, and provider characteristics. RESULTS: The study used responses from 203,903 patients to the SHEP-PCMH survey in FY2016 who received outpatient primary care services from 11,421 unique providers. Most (91\%) clinicians had no JLV utilization in the 6 months prior to the studied patient visit. Controlling for patient demographics, length of the patient-provider relationship, and provider and facility characteristics, being an early adopter of the JLV system was associated with a $14 \%$ (adj OR 1.14, $p<0.000$ ) increased odds that patients felt their provider was knowledgeable about their medical history. When evaluating the interaction between duration of patient-provider relationship and being an early adopter of JLV, a greater effect was seen with patientprovider relationships that were greater than 3 years (adj OR 1.23, $p<0.000$ ), compared to those less than 3 years. CONCLUSIONS: Increasing the interoperability of medical information systems has the potential to improve both patient care and patient experience of care. This study demonstrates that early adopters of an integrated view of electronic health records from multiple delivery systems are more likely to have their patients report that their clinician was knowledgeable of their medical history. With provider payments often linked to patient satisfaction performance metrics, investments in interoperability may be worthwhile.

Received December 17, 2017

Revised April 25, 2018

Accepted October 1, 2018

Published online October 18, 2018
KEY WORDS: electronic medical record (EMR); electronic health record (EHR); health information exchange (HIE); health information technology (HIT); interoperability; patient satisfaction.

J Gen Intern Med 34(1):132-6

DOI: $10.1007 / \mathrm{s} 11606-018-4708-\mathrm{Z}$

(c) Society of General Internal Medicine 2018

\section{INTRODUCTION}

The Institute of Medicine has strongly argued for the increased use of electronic health records (EHRs) based on existing evidence that EHRs improve the technical quality of care and adherence to evidence-based guidelines. ${ }^{1}$ The increasing prevalence of EHRs is also likely to influence the doctorpatient interaction relating to the emotional aspects of care such as patient satisfaction and patient adherence to care received. ${ }^{2,3}$

Veterans, like many other patient groups, receive healthcare in multiple settings. A recent study by Helmer et al. (2018) found state-level reliance on VHA for ambulatory care among veterans dually enrolled in VHA and Medicare ranged from 14 to $68 \%$. $^{4}$ This kind of fragmentation of care has been linked to coordination failure and increased risk of hospitalization for ambulatory care-sensitive conditions. ${ }^{5}$

The Joint Legacy Viewer (JLV) version 2.2, released on September 2014, is a web-based graphical user interface developed by the Veterans Administration (VA) and Department of Defense (DoD). While it does not transfer data, it supports viewing health data from the VA, DoD, and community partners. ${ }^{6}$ It provides one integrated interface to view complete patient health information such as allergy, immunization, laboratory records, medications, physician notes, problem list, and vital signs. Seamless access to the entire patient medical history from VA, DoD, and participating community partners has the potential to improve both clinical aspects of care and patient satisfaction with their provider interactions. JLV is available to all VA providers; providers decide at each patient encounter whether to use it.

Clinical data is readily available to assess clinical outcomes, but patient satisfaction is also important to physician-patient communication and a vital element in the treatment and 
prevention of many diseases. ${ }^{7}$ At the same time that investment in health information technology (HIT) and health information exchange (HIE) is increasing, there is little evidence regarding the impact of interoperable systems on the patient experience of care. Hsu et al. found that implementation of HIT in exam rooms translated to higher levels of patient satisfaction in regard to medical communication, but did not focus specifically on how the patient perceived the provider's knowledge of their medical history. ${ }^{8}$ Jarvis et al. found that while EHRs were associated with improved processes of care, there was no significant impact on patient experience of care. ${ }^{9}$ In this article, we build on the literature by measuring the relationship between provider use of an integrated EHR viewer and patient satisfaction with the provider's knowledge of the patient's medical history.

\section{METHOD}

\section{Study Design}

We conducted a retrospective cross-sectional analysis in FY2016 that compared provider use of JLV with patient responses from a satisfaction survey. The analysis compared patient perception of providers' knowledge of their medical history for providers who were using JLV during primary care outpatient visits in FY2016 to those who were not. This work was conducted for VA quality improvement and program evaluation purposes and was therefore exempt from Institutional Review Board review.

\section{Sample and Setting}

All patients seen in FY2016 at VA facilities for outpatient primary care services who also completed the satisfaction survey were eligible to be included in the analysis (patients are surveyed at most once in a year). Patients who saw providers other than physicians, physician assistants, or nurse practitioners $(123,150$ patients), and those who did not respond to the specific question of whether their provider seemed knowledgeable about their medical history $(31,405$ patients) or their health status over the past 12 months (6640 patients) were excluded from the study. Patient-provider interactions with greater than the 95th percentile of JLV utilization (19,966 patient-provider interactions) were also excluded from the study because of implausibly large values suggestive of tracking errors.

\section{Measures}

The VHA uses two tools to capture patient experiences - the Survey of Healthcare Experiences of Patients (SHEP) and Patient-Centered Medical Home (PCMH) surveys. The SHEP has been in use since 1994 and based on the CAHPS or Consumer Assessment of Healthcare Providers \& Systems survey instrument generally considered the industry standard for inpatient and outpatient care settings. ${ }^{10}$ The PCMH survey also known as the CAHPS PCMH survey includes standardized questions for adults and children in primary care settings to assess patient experiences with primary care over the last 12 months. $^{11}$

Outpatient primary care services were identified using VA clinic stop codes $(322,323,350)$ and patients must have had a visit to one of these clinics on the same day they received their SHEP/PCMH survey to be included. JLV utilization was assessed using the staff audit logs from the JLV system, tallying the number of provider utilizations of JLV over the 6 months prior to the patient-provider encounter that triggered the SHEP/PCMH survey. Of the 11,421 providers in the study sample, 10,426 (91\%) had no JLV utilization over the prior 6 months. There was also a significant group of providers with near-zero utilization, so providers with fewer than ten utilizations of JLV over the prior 6 months were classified as "nonJLV providers" while those with greater than or equal to ten were classified as "JLV providers." The categorization of whether a provider was using JLV or not was done at each provider-patient interaction. Because this categorization was based on prior interactions that typically involved other patients, it was largely independent from the patient under study, but indicated that the provider had the ability to access information in DoD health records if it was felt to be relevant. For provider-patient interactions with providers categorized as JLV users, the mean JLV utilization over the prior 6 months was 70.0, and the median was 39 with a minimum of 10 and a maximum of 326 .

The dependent variable was derived from the patient response to the survey question "In the Past 12 Months Did this Provider Know your Medical History?" and was coded as "Always" versus "Never/Sometimes/Usually." Of the final sample of patients, $67.4 \%$ responded affirmatively that their provider always seemed knowledgeable about their medical history.

Covariates included the duration of the patient-provider relationship, patient demographics (race, age, education), survey response rate by facility, provider type (physician vs physician assistant/nurse practitioner), fiscal month, and a rating of how likely previous patients were to report they felt the provider listened to them during their visit. There is a strong correlation $(0.57, p<0.000)$ between responses to this "provider listened" question and the primary dependent variable, so using the contemporaneous patient response from both the outcome and the covariate would lead to endogeneity bias. To avoid this, we used the historical rating of the provider over the prior 2 months from other patients to adjust for the provider's individual likelihood of being a "good listener."

Patient demographics (race, sex, education, health status, age) were self-reported on the SHEP/PCMH survey. Response rate to the SHEP/PCMH survey was calculated by facility-month as a percentage of patients sampled in that month that responded to the survey. Fiscal months (OctSep) were used to correspond with the sampling of the SHEP/PCMH survey. 


\section{Statistical Analysis}

Descriptive statistics (means, standard deviations, interquartile ranges) were used to explore the relationship between JLV use and patient satisfaction. We used a providerlevel random effects multivariate logistic regression of the dependent variable of provider awareness with a primary independent variable of JLV user (yes/no) based on the provider's use of JLV over the past 6 months at each provider-patient interaction. STATA $14^{12}$ was used for statistical analysis.

\section{RESULTS}

Of the 203,903 subjects in the final analytic sample, $84.7 \%$ were White, $10.7 \%$ were Black, $5.6 \%$ were Hispanic, and $4.4 \%$ were of other races. The majority $(82 \%)$ were aged 60 or older and $59.1 \%$ had some level of college education (Table 1). 94.8\% were male. Thirty-one percent had seen their provider for less than 1 year while $41 \%$ had seen their provider for $\geq 3$ years. Twenty-nine percent self-reported that their health status in the past 12 months was very good or excellent. $67.4 \%$ of subjects reported that their provider was always knowledgeable about their medical history.

The duration of patient/provider relationship was the variable most strongly associated with patient reports that their provider was always knowledgeable about their medical history (Table 2). However, after controlling for duration of the patient/provider relationship, in addition to patient and provider characteristics, patients of JLV providers were $14 \%$ more likely (adj $\mathrm{OR}=1.14, p<0.000$ ) to report that their provider was knowledgeable about their medical history. Patients of physician assistants or nurse practitioners were more likely than those of physicians to report that their provider was knowledgeable about their medical history (adj $\mathrm{OR}=1.09 ; 95 \% \mathrm{CI}=1.06-1.13$ ). The

Table 1 Characteristics of VA Patient-Centered Medical Home Survey Respondents (FY16 Seen in Primary Care)

\begin{tabular}{|c|c|}
\hline$(N=203,903)$ & $n(\%)$ \\
\hline \multicolumn{2}{|l|}{ Age } \\
\hline$<40$ & $5050(2.5)$ \\
\hline $40-59$ & $31,774(15.6)$ \\
\hline $60-79$ & $130,116(63.8)$ \\
\hline 80 and above & $36,962(18.1)$ \\
\hline \multicolumn{2}{|l|}{ Race } \\
\hline White & $172,678(84.7)$ \\
\hline Black & $21,792(10.7)$ \\
\hline Hispanic & $11,311(5.6)$ \\
\hline Other & $8936(4.4)$ \\
\hline \multicolumn{2}{|l|}{ Education } \\
\hline Some college & $120,570(59.1)$ \\
\hline \multicolumn{2}{|l|}{ Sex } \\
\hline Male & $193,377(94.8)$ \\
\hline Female & $10,526(5.2)$ \\
\hline \multicolumn{2}{|c|}{ Health status over the past 12 months } \\
\hline Poor/fair/good & $144,826(71.03)$ \\
\hline Very good/excellent & $59,077(29.0)$ \\
\hline
\end{tabular}

Table 2 Provider Use of Joint Legacy Viewer During Outpatient Primary Care Visits Impact on Patient Perception of Provider Knowledge of their Medical History

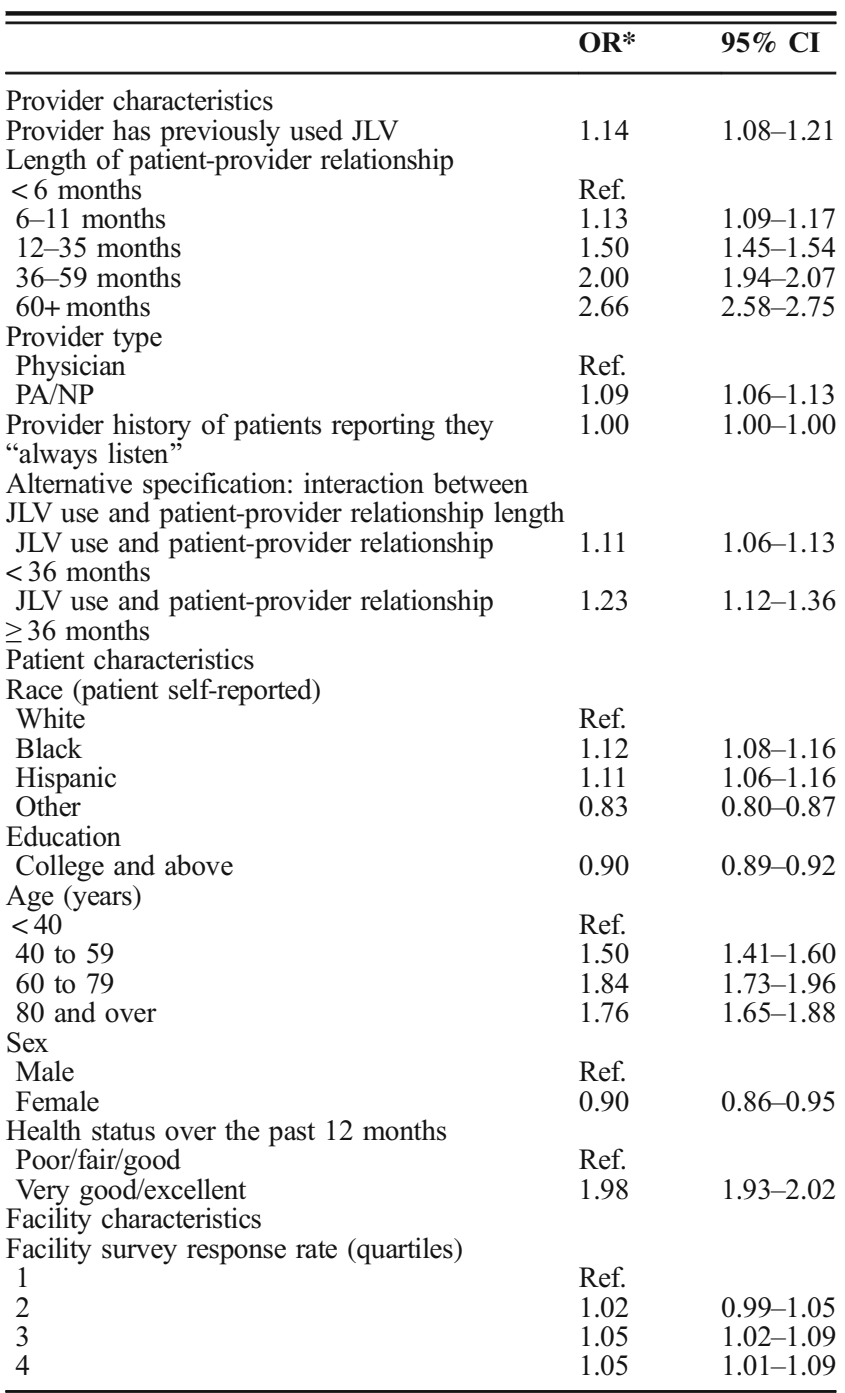

*Odds ratios estimated from random effects logistic regressions controlling for all variables shown in table and survey response rate by facility fiscal month

facility average survey response rate was also positively associated with patient reports that their provider was always knowledgeable.

A secondary analysis focused on the interaction of JLV use and patient-provider relationship, where the reference group was patients who had been seeing a non-JLV provider for less than 6 months. After testing each SHEP categorization for relationship length, we found that the highest impact on patient satisfaction was among patients who had seen their provider for 3 years or longer (adj OR $1.23, p<0.000)$. Patients who had seen their provider for less than 3 years also had a significant increase in satisfaction when the provider used JLV; however, the effect was much smaller than that of the 3 years and greater group (adj OR $1.11, p<0.05$ ). 


\section{DISCUSSION}

This analysis of VA data found that providers who access integrated data from more than one EHR are more likely to be rated by their patients as always knowledgeable about their patient's health history. Specifically, JLV providers were $14 \%$ more likely to have their patients report that their provider was knowledgeable about their medical history than providers who had not used JLV. By adjusting for providers' communication skills in prior clinical encounters, we were able to examine the relationship between JLV use to help reduce any endogeneity bias due to the specific patient-provider interaction that could be unrelated to actual provider knowledge.

Other studies ${ }^{13}$ have found that most present day ambulatory EHRs are designed for point-in-time documentation, but not equipped for a dynamic process such as coordination of care, or handling information exchange between practices. Investments in longitudinal, integrated EHR viewers have the potential to improve the entire process of care, and may be advantageous under pay for performance guidelines ${ }^{14}$ which focus on patient satisfaction.

Our secondary finding that the association between JLV use and satisfaction was most pronounced for encounters with longer patient-provider relationships has important implications for investment decisions. Although providers are more likely to use JLV with new patients (and the clinical benefits of JLV use may be most pronounced with new patients), the impact on patient satisfaction is strongest with established patients. One possible explanation for this finding could be that patient expectations are higher in a longer relationship and JLV use helps providers meet those expectations. Our findings suggest that if health systems wish to realize the benefits of interoperability investments on patient satisfaction, they should not focus these investments exclusively on new patients.

Limitations of this study include the limited duration of time available for monitoring the level of JLV utilization and the issue of provider factors that may confound results. The study was conducted on patients seen from October 2015 through September 2016 to correspond with the FY15 SHEPS PCMH survey. During that same time-period, JLV utilization was increasing; however, overall, only $13 \%$ of providers had any JLV utilization. We took into account provider characteristics such as training (physicians, PA/NP), the duration of the patient-provider relationship, and the rate with which other patients indicated the provider listened to them during their visits. However, despite these controls, there remains some possibility that other behaviors that give providers higher patient satisfaction scores may be correlated with use of the JLV system, potentially confounding our results.

In conclusion, this study provides evidence that a longitudinal viewer of multiple EHR data is associated with more positive patient experiences of care. With the increasing focus on patient satisfaction surveys in structuring pay for performance hospital reimbursements, investment in such technology may be warranted.
Acknowledgements: The authors wish to thank David Schmidt for helpful comments on prior versions of this work and for logistical assistance.

Corresponding Author: Steven D. Pizer, PhD; Department of Health Law, Policy, and Management Boston University School of Public Health, 715 Albany Street, Talbot 247 W, Boston, MA 02118, USA (e-mail:pizer@bu.edu).

Funding Information This research was supported by the VA Office of Health Informatics and by Grant Number PEC 16-0O1 from the VA Quality Enhancement Research Initiative (BUERI). Opinions and conclusions expressed are those of the authors and do not reflect the official position of the US Department of Veterans Affairs, the University of Utah, or Boston University.

\section{Compliance with Ethical Standards:}

Conflict of Interest: The authors declare that they do not have a conflict of interest.

\section{REFERENCES}

1. Dick RS, Steen EB, Detmer DE. The Computer-Based Patient Record. An Essential Technology for Health Care. 1997; 1-256.

2. Roter DL, Frankel RM, Hall JA, Sluyter D. The Expression of Emotion Through Nonverbal Behavior in Medical Visits. J Gen Intern Med 2006; 21(S1): S28-34. Available from: doi: https://doi.org/10.1111/j.15251497.2006.00306.x [Accessed 20 ${ }^{\text {th }}$ September 2017].

3. Waitzkin H. Doctor-Patient Communication: Clinical Implications of Social Scientific Research. JAMA 1984; 252(17): 2441-2446. Available from: doi:https://doi.org/10.1001/jama.1984.03350170043017 [Accessed September 20, 2017].

4. Helmer, D.A., Rowneki, M., Feng, X., Tseng, C.L., Rose, D., Soroka, O., Fried, D., Jani, N., Pogach, L.M. and Sambamoorthi, U., 2018. State-Level Variability in Veteran Reliance on Veterans Health Administration and Potentially Preventable Hospitalizations: A Geospatial Analysis. INQUIRY, 55, p.0046958018756216. Available from: DOI: https:// doi.org/10.1177/0046958018756216 journals.sagepub.com/home/inq [Accessed April 4, 2018].

5. Pizer, S.D. and Gardner, J.A., 2011. Is fragmented financing bad for your health? INQUIRY, 48(2), pp. 109-122. Available from: http:// journals.sagepub.com/doi/abs/10.5034/inquiryjrnl_48.02.02 [Accessed April 4, 2018].

6. Department of Veterans Affairs (VA): Office of Information and Technology (OI\&T). Joint Legacy Viewer (JLV) 2.5.1 User Guide: 1-67, December 2016. Available from: https://www.va.gov/vdl/documents/Clinical/Joint_Legacy_Viewer_(JLV)/jlv2_5_2_userguide.pdf[Accessed 10 ${ }^{\text {th }}$ April 2018].

7. Garrison GM, Bernard ME, Rasmussen NH. $21^{\text {st }}$-Century Health Care: The Effect of Computer Use by Physicians on Patient Satisfaction at a Family Medicine Clinic. J Fam Med 2002; 34(5): 362-8. https://s3. amazonaws.com/academia.edu.documents/46601611/st-century_ health_care_the_effect_of_com20160618-6895-jthcz.pdf? AWSAccessKeyId=AKIAIWOWYYGZ2Y53UL3A\&Expires $=1505932227 \&$ Signature=99J\%2B7NdnKQGDatTEvzOBeSc\%2BY\%2B4\%3D\&response-content-disposition=inline \%3B\%20filename\%3D21ST-CENTURY Health_Care_The_Effect_of_C.pdf [Accessed $20^{\text {th }}$ September 2017].

8. Hsu J, Huang J, Fung V, Robertson N, Jamison H, Frankel R. Health Information Technology and Physician-Patient Interactions: Impact of Computers on Communication during Outpatient Primary Care Visits. J Am Med Inform Assoc. 2005; 12(4): 474-80. Available from: https://doi. org/10.1197/jamia.M1741 [Accessed September 20, 2017].

9. Jarvis B, Johnson T, Butler $\mathbf{P}$, O'Shaughnessy $\mathbf{K}$, Fullam $\mathbf{F}$, Tran $\mathbf{L}$ Gupta R. Assessing the Impact of Electronic Health Records as Enabler of Hospital Quality and Patient Satisfaction. Acad Med 2013; 88(10): 1471-77. Available from: doi: https://doi.org/10.1097/ACM. Ob013e3182a36cab [Accessed September 20, 2017].

10. VA Information Resource Center (VIReC). Survey of Healthcare Experiences of Patients (SHEP) Data. SHEP Data Overview. Available from: http://vaww.virec.research.va.gov/SHEP/Overview.htm [Accessed 20th September 2017]. 
11. Wright S. Partnered Research with the Office of Performance Measurement: An Overview of Existing Data. VHA Office of Analytics and Business Intelligence. Available from: https://www.hsrd.research.va.gov/for_researchers/cyber_seminars/archives/962-notes.pdf [Accessed $20^{\text {th }}$ September 2017].

12. StataCorp. Stata Statistical Software: Release 14. College Station, TX: StataCorp LP.

13. McGrath JM, Arar NH, Pugh JA. The influence of electronic medical record usage on nonverbal communication in the medical interview.
Health Informatics J 2007; 13(2): 105-118. Available from: DOI: https:// doi.org/10.1177/1460458207076466 [Accessed September 20, 2017].

14. O'Malley AS, Grossman JM, Cohen GR, Kemper NM, and Pham HH. Are Electronic Medical Records Helpful for Care Coordination? Experiences of Physician Practices. J Gen Intern Med 2009; 25(3): 177-85. Available from: doi: https://doi.org/10.1007/s11606-009-1195-2 [Accessed September 20, 2017]. 